\title{
EDITORIAL
}

\section{El significado de las demandas "menores" en salud mental.}

Cuentan que hace muchos años, había un psiquiatra atareado y de sólida formación médica que, cuando los pacientes comenzaban a relatarle las circunstancias vitales de su malestar, este les respondía:

- ¿Le cuento yo mi vida? No, ¿verdad? Pues entonces usted limítese a contarme sus sintomas.

Y resulta curioso cómo aquella anécdota se ha materializado hoy en día, en muchos pacientes que ya no se pierden en detalles innecesarios, e incluso nos proporcionan ellos mismos directamente el diagnóstico:

- Tengo una depresión

O en otros tantos profesionales que han desarrollado una extraordinaria capacidad de desligar los síntomas del contexto en el que se desenvuelven.

Los trastornos mentales menores, comunes, subumbrales, las reacciones adaptativas, los códigos Z... forman un grupo de demandas caracterizadas por su elevada y creciente frecuencia en atención primaria y salud mental y su leve sintomatología en contraposición con los trastornos mentales graves. La nueva sociedad posmoderna, individualista y desprovista de los referentes anclados en instituciones y costumbres ya del pasado, probablemente ha favorecido el incremento de esta demanda. En cierta medida, el centro de salud mental y la atención primaria están llenando parte del vacío que han dejado las redes tradicionales de contención: familia, vecindario, sindicatos... y que los servicios sociales, ya limitados en intentar satisfacer necesidades básicas, no puede cubrir tampoco. Se trata de una demanda que busca "expertos" que gestionen la ansiedad y el malestar que produce este nuevo orden social donde parece que las relaciones humanas han sufrido cierta devaluación frente a la relación profesionalizada. Se ha producido una idealización de lo tecnológico y lo científico que sitúa a psiquiatras y psicólogos en los nuevos referentes de cómo hay que vivir la vida y afrontar sus vicisitudes.

En cualquier caso, este conjunto de consultas ha supuesto un reto asistencial que, a la vista de lo que está sucediendo en los últimos años, no estamos siendo capaces de abordar adecuadamente.

Dos factores se revelan hoy en día determinantes en la asistencia a estas demandas: unos servicios sanitarios cada vez más desbordados y, en esta época de recortes, más limitados en sus prestaciones, y la hegemonía entre psiquiatras y psicólogos, de una visión médica centrada en los síntomas y su resolución. La conjugación de ambos, ha plantado los cimientos para proporcionar, por dos vías distintas y aparentemente contrapuestas, una mala atención a esta población. 
Una primera vía, la más frecuente, conduce hacia una patologización masiva. Se fundamenta en la indicación de tratamiento a todo aquel que lo demande en los servicios sanitarios, por el mero hecho de hacerlo. El extraordinario crecimiento en la prescripción de antidepresivos o la expansión de las terapias que hablan de acompañamiento, apoyo o aconsejamiento, incluso en personas sanas aunque dolientes, lo certifican.

La otra vía nos lleva hacia una normalización forzada. Se produce cuando, desde una priorización exagerada de los recursos de salud mental, se atiende únicamente a los trastornos mentales graves y el resto de las demandas son reconducidas sistemáticamente a la atención primaria.

El peligro es que, por ambos caminos, el paciente puede convertirse en un sujeto ahistórico y descontextualizado. Es portador de un conjunto de síntomas que podemos tratar de forma indiscriminada desde nuestra vocación de ayuda y necesidad de tener respuestas para todo o, por el contrario, desconsiderar su atención especializada apelando a nuestros principios de justicia social y discriminación positiva con los más desfavorecidos. El respaldo definitivo, en todo caso, nos lo proporciona una nosología sesgada y simplificadora, de etiquetas estáticas, que no entiende de contextos, dimensiones y dinámicas.

En este punto, tal vez nos tengamos que preguntar desde dónde miramos a los pacientes y qué estamos dispuestos a escuchar. Podemos conformarnos con conseguir un listado de síntomas que se corresponda con una categoría diagnóstica que nos dirija sin más cuestionamientos a tratar y/o derivar. O podemos mirar a esa persona para atender sus síntomas, desde luego, pero inmersos en su historia vital y su contexto familiar, social, económico, laboral... y también su manera de afrontar las dificultades en el pasado y ahora, y el significado y atribución que le da a sus síntomas, y lo que espera de nosotros, y lo que demanda, y sus valores... No cabe duda de que esta opción de ampliar y escuchar de forma empática una narrativa global del paciente nos exige más, supone recabar mayor información que luego tenemos que organizar para interpretar y buscar hipótesis y explicaciones con esa persona de lo que piensa, siente y actúa. Sin embargo, esta aproximación es mucho más eficaz y resolutiva para el paciente y, por tanto, para los servicios sanitarios por varios motivos.

Una escucha empática global que trascienda los síntomas nos va a permitir conocer mejor al paciente y tomar una decisión clínica más adaptada a él en particular y no de forma estandarizada. Si el paciente precisa de un tratamiento, ya sea en salud mental o en atención primaria, nos ayuda a empezar a construir con él una alianza terapéutica que favorecerá su participación y compromiso con el mismo. Si por el contrario consideramos que el paciente tiene una reacción emocional normal, legítima y sana que no precisa ningún tratamiento, solo desde esta posición de es- 
EDITORIAL

cucha y colaboración podremos deconstruir su idea de que tiene un trastorno o de que precisa una atención sanitaria y resignificar sus síntomas como una respuesta emocional necesaria y adaptativa a la situación que está viviendo.

Todo esto, trabajando junto con nuestros compañeros de atención primaria, se puede traducir en una prestación sanitaria a estas demandas mucho más ajustada, sin patologización ni normalización forzada (en todo caso, normalización fundamentada) y con la premisa, como en cualquier disciplina sanitaria, de que siempre tenemos que intervenir en el nivel asistencial y terapéutico más bajo posible para evitar iatrogenia.

Probablemente, la mejora de la atención a este grupo de demandas no depende solo del tiempo de dedicación y los recursos sanitarios, sino también de cómo las miramos. De hecho, una perspectiva médica finalmente puede favorecer la cronificación de ciertos cuadros leves y producir un mayor dispendio de tiempo y recursos (incluida la factura farmacéutica).

En estos tiempos corremos el peligro de centrarnos en intentar resolver demandas con psicofármacos o con técnicas psicoterapéuticas, pero no en darles sentido. Una buena parte de las consultas "menores" no precisan que pretendamos suprimir los síntomas sino que los contextualicemos y, con el paciente, les otorguemos un nuevo significado fuera del ámbito sanitario. Y eso, si lo hacemos bien, podemos lograrlo la mayoría de las veces en una sola entrevista.

Alberto Ortiz Lobo 